\title{
Effects of lockdown over consumer behaviour and consumption practices covid-19: Pandemic review
}

\author{
Ekta Melkani, Manju Mehta and Kiran Singh
}

Received: 09.10.2020; Accepted: 24.11.2020

See end of the paper for authors' affiliations Ekta Melkani

Department of Family Resource Management, I.C. College of Home Sceince, C.C.S. Haryana Agricultural University, Hisar (Haryana) India

Email : ektamelkani@gmail.com
ABSTRACT : This review paper deals with the global studies of how consumers have been affected at a global level during past pandemics and how they are coping with the current pandemic of COVID-19 in world and in India. A relationship has been tried to be established of how situations and preparedness have been changed during pandemics in parts of government policies and consumers themselves. Lockdown has impacted the change in behavior among many consumers in different attributes of life like in electricity consumption, food habits and lifestyle factors. Agricultural sector has been widely impacted due to the lockdown and different farmers growing varied crops have been influenced differently.

KEY WORDS: Effects of lockdown, Consumer behaviour, Consumption practices, Covid-19

- HOW TO CITE THIS PAPER : Melkani, Ekta, Mehta, Manju and Singh, Kiran (2020). Effects of lockdown over consumer behaviour and consumption practices covid-19: Pandemic review. Asian J. Home Sci., 15 (2) : 429-433, DOI: 10.15740/HAS/AJHS/15.2/429-433. Copyright@ 2020: Hind Agri-Horticultural Society. 